\title{
INTEGRAÇÃO METABÓLICA NOS PERÍODOS PÓS-PRANDIAL E DE JEJUM - UM RESUMO
}

\author{
Sônia Valéria Pinheiro Malheiros ${ }^{1,2}$ \\ ${ }^{1}$ Pesquisadora Colaboradora, Departamento de Bioquímica, Instituto de Biologia - \\ UNICAMP \\ ${ }^{2}$ Professora Doutora Adjunta Disciplina de Bioquímica, Faculdade de Medicina de \\ Jundiaí - FMJ \\ *sonia.malheiros@uol.com.br
}

\section{Resumo:}

Sabe-se que a presença ou ausência de alimentos influencia drasticamente o metabolismo de carboidratos, lipídios e proteínas. E ainda, que cada tecido têm características metabólicas próprias. Este trabalho revisa o metabolismo dos principais combustíveis celulares nos períodos pós-prandial e de jejum considerando as especificidades metabólicas das seguintes células e tecidos: hemáceas, cérebro, fígado, músculo e tecido adiposo, enfocando a profunda integração metabólica existente nos organismos vivos.

\begin{abstract}
:
It is well known that the presence or absence of food can drastically influence the metabolism of carbohydrates, lipids and proteins. Furthermore, it is established that each different tissue has a characteristic metabolic profile. This work reviews the metabolism of main fuels of the cell considering the metabolic specificity of the following cell or tissues: red blood cell, brain, liver, muscle and fat, focusing the deep metabolic integration that occurs in living organisms.
\end{abstract}




\section{resumo}

Integração Metabólica nos Períodos Pós-prandial e de Jejum - Um

Logo após uma refeição, a maior parte dos carboidratos, aminoácidos e uma pequena parte dos triglicerídeos advindos da dieta são diretamente levados ao fígado pela veia porta $[1,2,3]$. A maior parte dos triglicerídeos advindos da dieta, no entanto, percorre um caminho diferente, eles migram pelo sistema linfático, caem na circulação sistêmica podendo ser metabolizados pelo fígado ou captados pelo tecido adiposo $[1,2,3]$. De um modo geral, a concentração dos nutrientes no sangue é extremamente controlada pelo fígado, que os capta e distribui. O fígado será o órgão central da manutenção da homeostasia de carboidratos $[1,2,4]$, lipídeos $[1,2,4]$ e proteínas $[1,2,4,5]$. No período de jejum a degradação de glicogênio, a proteólise muscular e lipólise são responsáveis por manter o aporte energético no organismo. É preciso considerar que em cada célula ou tecido exercendo papéis fisiológicos específicos as vias metabólicas tenham características próprias. Este artigo analisa o metabolismo de diferentes células (hemáceas) e tecidos (cérebro, músculos, fígado e tecido adiposo) enfocando as inter-relações teciduais que ocorrem no período pósprandial e no jejum, e também as características metabólicas próprias de cada tecido.

\section{Hemáceas}

As hemáceas, cuja principal função é o transporte de oxigênio, teriam sua função extremamente prejudicada caso, ao transportar o oxigênio por longos trajetos, como o fazem, se consumissem o mesmo. Portanto, o metabolismo da hemácea é predominantemente anaeróbico. Sem o aparato mitocondrial para a oxidação dos demais nutrientes, as hemáceas tornam-se dependentes da via glicolítica anaeróbica. O consumo de glicose nestas células ocorre de modo constante e independente do perfil nutricional. A captação da glicose pelos transportadores GLUT1 da membrana da hemácea independe da presença de insulina [1,3]. Nestas células, a via glicolítica culmina na produção constante de lactato, o qual será captado pelo fígado. O lactato produzido pelas hemáceas é convertido em glicose pela gliconeogênese hepática e é uma das fontes de manutenção da glicemia em jejum $[1,3,6]$.

\section{Cérebro}

O cérebro não tem qualquer reserva energética e por isso, independente do estado nutricional é necessário que haja um suprimento de glicose constante para este tecido. Os transportadores de glicose no SNC são do tipo GLUT1 e GLUT3, trabalham independente da presença de insulina, e juntos, garantem uma alta eficiência na captação da glicose neste tecido $[3,7]$. Além da glicose, os corpos cetônicos podem ser utilizados como substratos energéticos no SNC em situações especiais como veremos a seguir. No entanto, a independência de glicose neste tecido nunca é absoluta. Situações de hipoglicemia causam perturbações no funcionamento do SNC, que vão desde cefaléia, incoordenação de fala e motora, até alterações no eletroencefalograma e coma [2]. Os ácidos graxos não podem atravessar a barreira hemato-encefálica e, portanto, não podem suprir a demanda energética do SNC $[3,7]$.

Em situação fisiológica o consumo de glicose pelo SNC chega a $120 \mathrm{~g} / \mathrm{dia}$, só sendo menor que o consumo de glicose pelo músculo esquelético em atividade física [3]. A maior parte da energia utilizada pelo cérebro é usada na bomba $\mathrm{Na}^{+}-\mathrm{K}^{+}$ATPase [3], responsável pela repolarização do potencial de membrana nas células nervosas. 0 SNC, mesmo durante o sono, mantém um consumo constante de glicose, cerca de $60 \%$ do total da glicose consumida pelo restante do organismo [7], e é o grande consumidor deste nutriente.

\section{Fígado}

\section{O metabolismo de carboidratos no fígado}


No fígado, o transporte de glicose ocorre por transportadores GLUT2, os quais de modo eficiente, mantêm a concentração de glicose no hepatócito na mesma proporção com que este nutriente existe na circulação sangüínea $[1,3]$. No entanto, a glicose só poderá ser utilizada pelo tecido hepático após ser fosforilada. A enzima responsável por essa reação, a glicoquinase, possui baixa afinidade pela glicose $[1,3,6]$, assim, o fígado só irá fosforilar e garantir a permanência da glicose dentro das células hepáticas, uma vez que haja concentração suficientemente alta de glicose na circulação. Isso ocorre, porque o fígado pode usar outros substratos energéticos como ácidos graxos ou aminoácidos como fonte energética. Apesar da insulina não influenciar a captação de glicose nas células hepáticas, influencia profundamente a utilização da glicose por estas células. A glicose só será utilizada pelo fígado como nutriente preferencial quando a razão insulina/glucagon for suficientemente alta para ativar a via glicolítica $[1,3,6]$. O alto aporte de glicose, juntamente com a presença de insulina também estimularão a síntese de glicogênio, e, neste momento, o fígado passa a ser um armazenador de glicose $[1,3,6]$. Caso contrário, o fígado fará exatamente o oposto, será um exportador de glicose.

No momento de jejum, quando houver predomínio do glucagon sobre a insulina, a glicogenólise será ativada e o fígado passa a exportar a glicose que havia armazenado sob a forma de glicogênio. Como o glicogênio é uma reserva limitada e somente pode suprir a demanda de glicose no organismo por algumas horas, o fígado lança mão de outro recurso, a gliconeogênese $[1,3,6]$.

A gliconeogênese ocorre predominantemente no tecido hepático pelo estímulo do glucagon e é simultânea a glicogenólise hepática $[1,3,6]$. Enquanto houver glicogênio, a velocidade da gliconeogênese é pequena, no entanto, esta via ocorrerá em velocidade máxima após a exaustão do glicogênio hepático $[1,3,6]$. Portanto, no jejum prolongado, a glicemia é mantida somente pela gliconeogênese, o que significa um custo metabólico importante, pois esta via está relacionada à perda significativa de massa muscular e de tecido adiposo que acompanham o jejum $[1,3,6]$. É preciso lembrar que a síntese de glicose que ocorre no fígado durante períodos de jejum prolongados tem como principais precursores aminoácidos, advindos do músculo esquelético, glicerol, advindo da mobilização de triglicerídeos do tecido adiposo e lactato, advindo das hemáceas, e tendo como fonte de energia a intensa betaoxidação dos ácidos graxos liberados pela mobilização dos triglicerídeos $[1,6]$. Mesmo com a chegada de alimentos a produção de glicogênio a partir de aminoácidos provenientes da dieta pode continuar ocorrendo no fígado por algum tempo. Isto é chamado de gliconeogêse pós-prandial e ocorre para garantir um adequado armazenamento de glicogênio no fígado $[8,9]$.

\section{O metabolismo lipídico no fígado}

No período pós prandial, estimulado pela insulina, os ácidos graxos podem ser sintetizados em alta velocidade pelo fígado a partir de moléculas de acetil-coA $[1,3,6]$. Os ácidos graxos sintetizados pelo fígado serão exportados através das lipoproteínas transportadoras VLDL até o tecido adiposo, local onde serão armazenados $[1,3,7]$. Toda vez que o consumo de alimentos exceder a demanda energética teremos 0 acúmulo de reservas (glicogênio e triglicerídeos) $[1,3,6]$. No entanto, a capacidade de armazenamento de glicogênio é bastante limitada quando comparada a de triglicerídeos. Veja que a capacidade total do fígado armazenar glicogênio é em torno de $70 \mathrm{~g}$ e do músculo esquelético $120 \mathrm{~g}[3,7]$, mas o tecido adiposo pode conter dezenas de quilogramas de triglicerídeos. A capacidade de transformar excessos alimentares em lipídeos é praticamente ilimitada e toda vez que houver desequilíbrio neste processo teremos a obesidade. 
Em situação de jejum, no entanto, o fígado capta ácidos graxos liberados pela mobilização de triglicerídeos do tecido adiposo, os quais serão utilizados para a síntese de corpos cetônicos $[1,3,6]$. A cetose é favorecida, pois, o outro caminho possível para a utilização dos ácidos graxos, a beta-oxidação, está inibida no fígado neste momento, já que há um desvio do oxaloacetato para a gliconeogênese, diminuindo a velocidade do ciclo do ácido cítrico $[1,3,6]$.

A produção de corpos cetônicos pelo fígado tem como principal objetivo fornecer um nutriente alternativo à glicose, para os tecidos extra-hepáticos. O SNC, por exemplo, adapta-se paulatinamente a chegada do novo nutriente e após algumas semanas inverte sua preferência nutricional passando de consumidor exclusivo de glicose (120g/dia) a consumidor preferencial de corpos cetônicos (100g/dia), embora seja sempre dependente de glicose, mesmo que em pequena proporção ( $40 \mathrm{mg} / \mathrm{dia})$ [7]. A profunda adaptação do SNC em relação à fonte energética se deve ao fato de que no jejum, a manutenção continuada da gliconeogênese significa importante depleção de proteínas do músculo esquelético, assim, caso a gliconeogênese fosse a única forma de suprimento energético, haveria uma debilidade protéica importante no organismo $[3,7]$. Por outro lado, a manutenção da cetose implica importante perda de lipídeos do tecido adiposo, uma reserva imensamente maior do que a de proteínas, e, portanto, quantitativamente mais disponível. É mantendo uma gliconeogênese moderada e intensificando a cetose que o organismo pode suportar um jejum prolongado por períodos bastante longos de tempo, de 30 a 60 dias $[6,7]$.

O papel do fígado como fornecedor energético do jejum, seja ele curto ou longo, exportando glicose ou corpos cetônicos para o restante do organismo, é fundamental para manter o funcionamento adequado do SNC e de outras células e conseqüentemente, para a manutenção da vida.

\section{O metabolismo protéico no fígado}

No período pós-prandial, quando a concentração de aminoácidos na corrente circulatória é alta, a oxidação completa de amino-ácidos fornece uma quantidade de energia significativa para o tecido hepático. Os aminoácidos podem ser totalmente oxidados pelo fígado, ou ainda, ser convertidos em glicose ou corpos cetônicos $[1,5,6]$. A produção de glicogênio a partir de aminoácidos provenientes da dieta (gliconeogênese pós-prandial) é particularmente estimulada por dietas ricas em proteínas e pode persisitir por algum tempo mesmo após o término de uma refeição $[8,9]$. Nos momentos de jejum, o fígado passa a receber aminoácidos do tecido muscular priorizando a gliconeogênese. O fígado participa ativamente do catabolismo protéico, já que o ciclo da uréia é exclusivo do tecido hepático, e é a forma preferencial de excreção de nitrogênio advindo da proteólise $[1,5,6]$.

Por outro lado, o fígado é responsável pela síntese de todas as proteínas plasmáticas, com exceção das imunoglobulinas as quais são sintetizadas pelos linfócitos $[2,10]$. A manutenção da concentração de proteínas circulantes nos valores adequados 6-8 g/dL exige um intenso trabalho de síntese protéica hepática [2].

\section{Tecido Muscular}

No músculo, a utilização de corpos cetônicos e ácidos graxos livres pode substituir a de glicose. No entanto, em situações de intensa atividade física, o metabolismo anaeróbico é favorecido, o que significa, que nesses momentos, o músculo será mantido principalmente pela utilização anaeróbica da glicose $[11,12]$. Isto justifica, a necessidade do músculo esquelético e cardíaco, manterem uma reserva de glicose, o glicogênio $[1,3,6,7]$. O glicogênio muscular, diferentemente do hepático, somente alimenta o próprio músculo, pois há ausência da enzima glicose-6fosfatase nas células musculares, de tal modo que a glicose liberada pelo glicogênio muscular mantenha-se fosforilada e seja incapaz de ser transportada para fora da 
célula $[1,3,6]$. A contribuição do glicogênio armazenado no músculo é fundamental para garantir a eficiência do trabalho muscular, principalmente quando é exigida do organismo uma atividade física intensa num período muito curto de tempo [11], como por exemplo, em exercícios de explosão, corridas de 400 metros ou provas de natação de 100 metros, ou ainda, em exercícios de força (musculação).

A captação de glicose no músculo ocorre pelos transportadores GLUT4, os mesmos que aparecem no tecido adiposo, e é extremamente dependente da ação da insulina $[3,13,14]$. A insulina aumenta o número de receptores GLUT4 expostos nas membranas celulares musculares e do tecido adiposo, porque estimula a mobilização destes receptores dos locais de armazenamento e sua migração para a membrana plasmática $[3,13,14]$. Outra ação da insulina no tecido muscular é a inibição da degradação protéica com favorecimento da síntese de proteínas $[15,16]$, de tal modo que dietas adequadas em aminoácidos e carboidratos tornam-se importantes coadjuvantes para a obtenção de hipertrofia muscular induzida pelo exercício físico [16].

No músculo esquelético em alta atividade a velocidade da glicólise é maior do que a do ciclo do ácido cítrico, então, uma grande parte do piruvato será convertido a lactato, o qual é captado pelo fígado, tornando-se substrato para a gliconeogênese $[1,3,6,11,17]$. Nesta situação fígado e músculo estabelecem uma relação de interdependência, o músculo consome glicose de maneira importante, produzindo lactato, o lactato é levado ao fígado pela corrente circulatória e lá é novamente convertido em glicose $[1,3,6,11]$, este ciclo de reações, é conhecido como ciclo de Cori, conforme ilustrado na Figura 1.

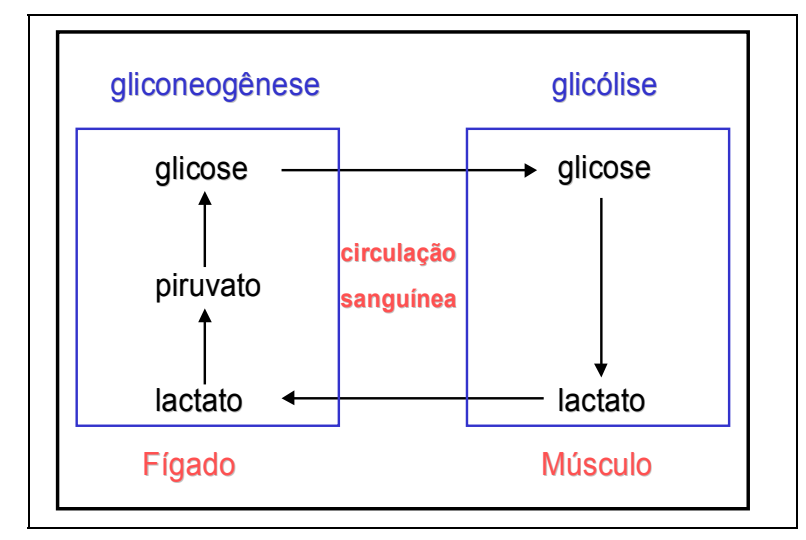

Figura 1: Ciclo de Cori.

Parte do piruvato produzido no músculo é convertido em alanina por reação de transaminação, e esta alanina, também irá alimentar a via de gliconeogênese hepática $[1,3,6]$. Em períodos de trabalho muscular intenso, ou ainda, durante o jejum prolongado, ocorre uma proteólise importante, e liberação do aminoácido alanina que funciona como importante substrato da gliconeogênese nestas situações $[1,3,6]$. Nos primeiros dias de jejum, a proteólise muscular é intensa, cerca de $75 \mathrm{~g} / \mathrm{dia}$, e após 3 ou 4 dias de jejum, passa a ocorrer em menor escala, cerca de $20 \mathrm{~g} /$ dia. As proteínas musculares devem ser poupadas após alguns dias de jejum, pois a reserva protéica é limitada, corresponde a $6 \mathrm{Kg}$ de massa muscular, para um indivíduo adulto de $70 \mathrm{Kg}$, e seria insuficiente para manter a glicemia por períodos maiores que duas semanas [7]. Assim, após um período de 3 ou 4 dias de jejum, o SNC vai substituindo o uso de glicose pelo de corpos cetônicos o que permite uma menor velocidade da proteólise muscular e conseqüentemente da gliconeogênese [7]. Em todo o caso, o músculo é a principal fonte de aminoácidos durante a inanição e será o grande alimentador da gliconeogênese nos períodos prolongados de jejum. 
Nos períodos de exercício físico moderado e de longa duração, o principal combustível para o tecido muscular passa a ser os lipídeos, e nesse sentido, os depósitos de triglicerídeos do próprio músculo assumem especial importância $[11,12,18]$. Em todo o caso, o músculo cardíaco parece dar prioridade aos corpos cetônicos, preferindo-os inclusive à glicose [7].

Como foi discutido acima, o tecido muscular pode utilizar vários substratos energéticos para garantir a eficiência do trabalho muscular. O tipo de substrato energético utilizado pelo músculo é determinado primariamente pela intensidade e duração do exercício, mas pode ser influenciado pelo nível de treinamento, dieta e fatores externos que poderiam modificar a resposta metabólica ao exercício $[11,12]$. Isto não significa que qualquer que seja o combustível preferencialmente utilizado haja exclusão dos demais, e sim, que há uma combinação de diferentes fontes de energia para um mesmo tecido.

\section{Tecido adiposo}

O tecido adiposo distribui-se sob o tecido subcutâneo, porém com tendência de acumular-se na cavidade abdominal e no músculo esquelético, e atinge cerca de $15 \%$ do peso de um indivíduo normal, isto é, cerca de $15 \mathrm{~kg}$ para um indivíduo adulto de $70 \mathrm{~kg}[3,7]$. Este grande volume lipídico é sem sombra de dúvida a maior reserva energética do organismo, e é caracterizado pelo acúmulo de grandes quantidades de triglicerídeos (TG) nas células adiposas $[1,3,6]$. A grande parte dos ácidos graxos que constituirão a moléculas de TG, chegam ao tecido adiposo transportados pelas lipoproteínas plasmáticas [1-3]. A síntese de TG, a partir de moléculas de glicerol-3fosfato e ácidos graxos ou a hidrólise, da molécula de TG são processos regulados pela disponibilidade de glicose nas células do tecido adiposo $[3,7]$. A entrada de glicose no tecido adiposo é feita pelos receptores GLUT4 dependentes da ação da insulina [3], e, assim, quando a razão insulina/glucagon for alta, o glicerol-3-fosfato é produzido no tecido adiposo pela redução da di-hidroxiacetona fosfato, intermediária da via glicolítica e novas moléculas de TG podem ser armazenadas [7].

No entanto, quando a razão insulina/glucagon diminui, a disponibilidade de glicose diminui. Com a diminuição da produção de glicerol-3-fosfato, a síntese de TG no tecido adiposo será dificultada. Por outro lado, quando a presença de insulina está diminuída e a de glucagon aumentada, as enzimas lipases que promovem a quebra de TG em ácido graxo e glicerol, serão ativadas, e assim, tanto ácidos graxos como glicerol, serão liberados para a corrente circulatória e serão captados pelo fígado $[3,19]$. Os hormônios T3 e T4, o hormônio do crescimento $(\mathrm{GH})$ e o cortisol também acionam a via lipolítica por aumento do $A M P C$, de modo semelhante ao glucagon e às catecolaminas.

De um modo geral podemos afirmar que a oferta de nutrientes garante uma série de condições que culminam na ativação das vias anabólicas, é o momento propício para o armazenamento. No entanto, no período de jejum que se segue a uma refeição as células passam ter um metabolismo predominantemente catabólico. Os principais, reservatórios energéticos, como glicogênio, triglicerídeos e proteínas serão mobilizados para suprir a carência energética do organismo. Vimos também que, em casos de jejum prolongado, uma série de adaptações metabólicas ocorre para garantir o funcionamento do organismo, sendo que a produção e utilização de corpos cetônicos passa ter uma importância ímpar na manutenção da vida.

\section{Referências Bibliográficas}


[1] D.L. Nelson, M.M. Cox (2005) Lehninger Principles of Biochemistry. 4th ed., Freeman and Company, New York.

[2] J.B. Henry (1999) Diagnóssticos Clínicos e Tratamento por Métodos Laboratoriais. Manole, São Paulo.

[3] D. Voet, J.G. Voet, C.W. Pratt (2002) Fundamentos de Bioquímica. Artmed, Porto Alegre.

[4] M.E. Shils, J.A. Olson, M. Shike et al. (2003) Tratado de nutrição moderna na saúde e doença. 9th ed., Manole, Baruer.

[5] J.T. Brosnan (2000) Glutamate, at the interface between amino acid and carbohydrate metabolism. J. Nutr. 988S-990S.

[6] A. Marzzoco, B.B. Torres (1999) Bioquímica Básica. 2nd ed., Guanabara-Koogan, Rio de Janeiro.

[7] L. Stryer (1992) Bioquímica. 3rd ed., Guanabara-Koogan, Rio de Janeiro.

[8] G.I. Shulman, B.R. Landau (1992) Pathways of glycogen repletion. Physiol. Rev. 72,1019-1035.

[9] A.C. Guyton, J.E. Hall (2002) Tratado de Fisiologia Médica. Guanabara Koogan, Rio de Janeiro.

[10] C.A. Burtis, E.R. Aswood (1998) Tietz Fundamentos de Química Clínica. Guanabara Koogan, Rio de Janeiro.

[11] M. Hargreaves (2000) Skeletal muscle metabolism during exercise in humans. Clin. Exp. Pharmacol. Physiol. 27(3),225-228.

[12] R. Curi, C. Lagranha, J.R.G. Júnior et al (2003) Ciclo de Krebs como fator limitante na utilização de ácidos graxos durante o exercíxio aeróbico. Arq. Bras. Endocrinol. Metab. 47(2),135-143.

[13] L.J. Wardzala, B. Jeanrenaud (1981) Potential mechanism of insulin action on glucose transport in the isolated rat diaphragm. Apparent translocation of intracellular transport units to the plasma membrane. J. Biol. Chem. 256,7090-7093.

[14] A. Klip, M.R. Paquet (1990) Glucose transport and glucose transporters in muscle and their metabolic regulation. Diabetes Care. 13,228-243.

[15] J. Grizard, D. Dardevet, M. Balaje (1999) Insulin action on skeletal muscle protein metabolism during catabolic states. Reprod. Nutr. Dev. 39(1),61-74.

[16] K.D. Tipton, R.R. Wolfe (2001) Exercise, protein metabolism, and muscle growth. Int. J. Sport. Nutr. Exerc. Metab. 11(1),109-132.

[17] Y. Ohira, I. Tabata (1992) Muscle metabolism during exercise: anaerobic treshold does not exist. Ann. Physiol. Anthropol. 11(3),319-323.

[18] A.E. Jeukendrup, W.H. Saris, A.J. Wagenmakers (1998) Fat metabolism during exercise: a review. Part I: fatty acid mobilization and muscle metabolism. Int. J. Sports Med. 19(4),231-244.

[19] P. Felig (1970) Glucagon: physiologic and diabetogenic role, N. England. J. Med. 283, 149-150. 